\title{
The Regulation and Interactions of the Hypoxia Inducible Factor Pathway in Carcinogenesis and Potential Cancer Therapeutic Strategies
}

\author{
Niraj Shenoy*\#, Makardhwaj Shrivastava*, Vineeth Sukrithan, Dimitra Papaspyridi, \\ Karine Darbinyan \\ Albert Einstein College of Medicine, Jacobi Medical Center, Bronx, NY, USA \\ Email: ${ }^{\text {knirajshenoy@gmail.com }}$
}

Received 21 May 2015; accepted 13 June 2015; published 17 June 2015

Copyright (C) 2015 by authors and Scientific Research Publishing Inc.

This work is licensed under the Creative Commons Attribution International License (CC BY). http://creativecommons.org/licenses/by/4.0/

\section{(c) (i) Open Access}

\begin{abstract}
The Hypoxia Inducible factor (HIF) pathway is known to be constitutionally active in various cancers and is the dominant pathway in some cancers such as VHL mutant clear cell Renal cell carcinoma. HIF-1 $\alpha$ and HIF-2 $\alpha$ overexpression is known to be important for tumor cell proliferation, maintenance of stemness and angiogenesis. There has been growing interest in therapeutic strategies targeting the HIF pathway over the last decade. We review in this section the role of hypoxia inducible factor pathway in carcinogenesis, its crosstalk with other pathways and potential cancer therapeutic strategies targeting the HIF pathway, its upstream regulators and downstream signaling.
\end{abstract}

Keywords

Hypoxia Inducible Factor (HIF), Cancer Therapy

\section{Introduction and Brief Overview of the HIF Pathway}

Under normoxic conditions, prolyl hydroxylases in the presence of Fe2+ and 2-oxoglutarate (2-OG), hydroxylate the proline residues in the Oxygen Degradation Domain of the $\alpha$ subunit of HIF- $\alpha$. The hydroxylated HIF- $\alpha$ then binds to VHL and undergoes polyubiquitination and proteasomal degradation. Under hypoxic condi-

\footnotetext{
*Equal contribution.

"Corresponding author.
}

How to cite this paper: Shenoy, N., Shrivastava, M., Sukrithan, V., Papaspyridi, D. and Darbinyan, K. (2015) The Regulation and Interactions of the Hypoxia Inducible Factor Pathway in Carcinogenesis and Potential Cancer Therapeutic Strategies. Journal of Cancer Therapy, 6, 511-521. http://dx.doi.org/10.4236/jct.2015.66055 
tions, the HIF- $\alpha$ proteins are not hydroxylated, leading to stabilization and translocation to the nucleus where they combine with constitutionally expressed HIF-1 $\beta$ to form heterodimers that bind to hypoxia response elements in a wide range of promoters and induce the expression of target genes. The pattern of transcription mediates cellular responses to hypoxia and can up-regulate the expression of multiple genes that contribute to cancer progression through survival, angiogenesis, invasion and metastasis. It is therefore not surprising that there has been growing interest in targeting the HIF pathway as a potential cancer therapeutic strategy.

\section{Interaction of the HIF Pathway with Other Pathways Involved in Carcinogenesis}

\subsection{Phosphatidylinositol 3-Kinase (PI3K)/Protein Kinase B (AKT)/Mammalian Target of Rapamycin (mTOR) Pathway}

PI3K/AKT/mTOR pathway is implicated in HIF protein synthesis in certain types of cancers [1]-[4]. Activation of receptor tyrosine kinases (ex-EGFR, VEGFR, HGF, FGFR etc.) by their ligands stimulates mTOR via PI3K/ AKT signaling thereby activating the translation of HIF-1 $\alpha$ mRNA to protein [4]-[6]. AKT enhances translation of HIF-1 $\alpha$ via mTOR dependent and mTOR independent pathways [7]. Inactivating mutations of tumor suppressor PTEN leads to enhanced PI3K levels, thereby augmenting the downstream HIF pathway.

\subsection{RAS-RAF-MEK-ERK Pathway}

Activating mutations of KRAS occurs in 35\% - 40\% of colon cancers [8]. Kikuchi et al., in their study on caco2 cell line, demonstrated increased hypoxic induction of HIF-1 $\alpha$ probably mediated by PI3K pathway [9].

Kang et al. showed that binding of RAGE (receptor for advanced glycation end products) to KRAS mediated HIF-1 $\alpha$ induction thereby promoting pancreatic tumor growth under hypoxic conditions [10]. They further postulated that RAGE production is augmented under hypoxic conditions by NFKB. So under hypoxic conditions $\mathrm{NF} K \mathrm{~B}$ leads to increased production of RAGE which binds to KRAS thereby effecting the downstream signaling via RAF-MEK-ERK and PI3K-AKT leading to increased translation and stabilization of HIF-1 $\alpha$. Role of NFKB in upregulation of HIF-1 $\alpha$ via AkT was also shown in a study on prostrate cancer cells by Sun et al. [11].

\subsection{Tumor Suppressor Genes-VHL and p53}

Under normoxic conditions the VHL gene product pVHL, degrades the hydroxylated HIF-1 $\alpha$ [12]. Under hypoxic conditions or deficiency of functional VHL tumor suppressor protein, the HIF pathway gets activated, enabling the rapid proliferation of tumor cells [13] [14]. Defective VHL function leading to HIF-1 $\alpha$ activation has also been linked to suppression of E-cadherin (homophilic cell adhesion molecule with anti-invasive properties) expression in cancers [15]-[17]. Evans et al. demonstrated increased E-cadherin expression in clear cell renal cell carcinoma cell line by using RNA interference-mediated knockdown of HIF-1 $\alpha$ [18].

In contrast to VHL, the interaction between TP53 and HIF is complex, with both shown to affect the other's functioning [19]. HIF $1 \alpha$ acting via inhibition of MDM2 has been shown to stabilize TP53 and increases its level [20], but Hammond et al. postulated that hypoxia induced TP53 is not coupled to the most common p53 target genes like CBP (CREB-binding protein) and p300 [21].

TP53 itself causes degradation of HIF- $1 \alpha$ (self regulatory loop of HIF- $1 \alpha$ ). Ravi et al. demonstrated increased HIF-1 $\alpha$ protein level in p53 deficient cells and showed that p53 promoted ubiquitination and proteasomal degradation of HIF- $1 \alpha$ in p53 sufficient cells [22]. However, mutated TP53 does not degrade HIF-1 $\alpha$ thereby increasing its levels. The presence of increased HIF-1 $\alpha$ and mutated TP53 has been shown to be associated with aggressive phenotype and adverse prognosis in various cancer types [23] [24].

\subsection{Role of HIF-1 $\alpha$ and Interaction with Pathways Involved in Epithelial-Mesenchymal Transformation (EMT), Self Renewal and Stemness of Malignant Cells}

The role of HIF- $1 \alpha$ and HIF- $2 \alpha$ in regulating EMT and stemness properties has been demonstrated in multiple studies [25]-[27]. Rui et al. demonstrated that HIF-1 $\alpha$ under low oxygen tension regulates the expression of Bmi1 directly with a boost from Twist. Expression of Bmi1 induces EMT whereas silencing Bmi1 expression reverses hypoxia induced EMT [28]. They also demonstrated the role of PI3K/Akt/Snail signaling as a downstream mediator of action of Bmi1 in promoting EMT [28] similar to a previous study by Guo et al. [29]. 
Bmi has been shown as essential mediator of Twist1-induced EMT [30] and also EMT by suppression of PTEN [31]. Furthermore HIF-1 $\alpha$ induces Twist expression under hypoxic conditions [32]. Interestingly, it has been suggested in the recent past that HIF may be a link between coagulation disorders and metastasis via thrombin mediated upregulation of HIF-1 $\alpha$-induction of Twist [33].

Bmi1 is an important critical component of polycomb repressive complex, that mediates stemness and selfrenewal [34]-[36], and its elevated expression correlates with advanced stage and unfavourable overall survival [29]. Furthermore, effects of hedgehog signaling in self-renewal of malignant cells have been demonstrated to be mediated via Bmi1 [37]. Along with Twist1, Bmi1 have been shown to downregulate E-cadherin and p16INK4a (an important cell cycle regulator) [30]. Bmi1 may thus be extrapolated as an important downstream mediator involved in various aspects of tumor growth. Blocking HIF-1 $\alpha$ (which upregulates production of Bmi1) may mitigate these multiple steps in tumorigenesis, tumor stem cell development, self renewal, invasion and metastasis.

TGF- $\beta$ pathway has also been implicated in hypoxia mediated EMT in liver [38]. Han et al. demonstrated that the EMT effect of TGF $\beta-1$ is mediated through HIF. Overexpression of prolyl hydroxylase-2 (which inhibits HIF-1 $\alpha$ ) almost completely inhibited TGF $\beta$-1 induced EMT. Increased SMAD2/SMAD3 level (components of the TGF $\beta$ pathway) was shown to inhibit prolyl hydroxylase leading to accumulation of HIF-1 $\alpha$ [39]. Another study has demonstrated this relationship between HIF-1 $\alpha$ and TGF- $\beta /$ Smad2/3 signaling [40].

HIF-1 $\alpha$ upregulates Survivin, a member of the "Inhibitor of apoptosis/IAP" family [41] [42]. Inhibition of Survivin has in turn been demonstrated to reduce HIF- $1 \alpha$ and TGF- $\beta$ in a study on salivary adenocarcinoma [43].

\subsection{HIF and Sonic Hedgehog Signaling (SHH)}

Recent studies have also shown the involvement of Sonic Hedgehog (SHH) signaling as a modulating pathway for the HIF- $1 \alpha$ in tumoral migration, proliferation and invasiveness. In their study on Neurobalstoma cells, Chen et al. demonstrated significant up-regulation of HIF- $1 \alpha$ level associated with overexpression of SHH components [44]. They also demonstrated reversal of pro-migration and proliferative effects of HIF-1 $\alpha$ by disrupting SHH signaling [44]. Similarly an interplay in the SHH signaling and HIF-1 $\alpha$ was demonstrated by Onishi et al. in their study on pancreatic cancer [45]. Lei et al. demonstrated role of HIF-1 $\alpha$ and SHH signaling in EMT in pancreatic cancer model [46].

\subsection{HIF and NOTCH Signaling-Cell Differentiation}

Under hypoxic conditions HIF-1 $\alpha$ binds to the intracellular domain of Notch and augments the downstream responses of the Notch ICD/ CSL transcription complex [47]. In order to elucidate the correlation between the two pathways Irshad et al. studied the gene signatures in Human glioblastoma gliomaspheres and monolayer cultures [48]. They observed up-regulated mRNA of HIF-1 $\alpha$ and its downstream targets-PGK1, VEGF, CA9 and OPN and also the components of Notch signaling namely Notch1, Notch3, Jag1, Dll1, Hes1, Hes6 and Hey1. In the gene cluster analysis they found the best association between PGK1 and OPN with notch signaling. Similarly the Notch subset that was maximally associated with overexpression of hypoxia markers comprised of Notch1/ Dll1/Hes1/Hes6/ Hey1/Hey2 [48].

HIF-1 $\alpha$ and Notch signaling interdependence has been implicated in maintaining the cells in undifferentiated state [49]. HIF mediated Increased Dll4-notch-hey2 signaling has also been shown in endothelial progenitor cells suggesting a role of this cross-talk in tumor angiogenesis [50]. Another complexity to this pathway interaction was suggested in a study which demonstrated that the Notch intracellular domain might be sequestering Factor-inhibiting HIF-1(FIH-1) away from HIF-1 $\alpha$ thus allowing downstream effects of HIF-1 $\alpha$ under hypoxic conditions [51].

\subsection{HIF and MITF (Microphthalmia Associated Transcription Factor)}

MITF enhances the transcription of HIF- $1 \alpha$. In normal cells under normoxic condition, SUMO binds to MITF and decreases the transcription of HIF- $1 \alpha$ but in hypoxia, SUMO is released from MITF, resulting in increased transcription of HIF1 $\alpha$. However, the MITF (E318K) mutant seen in some cases of melanoma is resistant to sumoylation, resulting in increased transcription of HIF1 $\alpha$ even under normoxic conditions [52] [53]. 


\subsection{HIF and Chemokines}

Chemokine receptor 4 (CXCR4) is a cell surface receptor that has been implicated in mediating invasion and metastasis in many cancers [54]-[56]. Phillips et al. demonstrated dramatic expression of CXCR4 under hypoxic conditions and also by EGFR in non-small cell lung cancer (NSCLC) via HIF-1 $\alpha$ dependent transcription [57].

Likewise, Li et al. studied the role of CCR7 and HIF in NSCLC. They demonstrated HIF-1 $\alpha$ mediated overexpression of CCR7 gene which, via ERK1/2 pathways enhanced invasion and migration of NSCLC cells under hypoxic conditions [31]. Increased CCR7 expression via HIF-1 $\alpha$ has been also shown to mediate invasiveness in breast cancer cells [58].

\subsection{HIF and Cellular Metabolism}

As noted above, HIF is an important driving force modulating many steps in cancer progression-angiogenesis, invasion and metastasis. Its role in cell survival and proliferation is underlined by its effect on cellular metabolism-the Warburg effect [59] [60]. HIF-1 $\alpha$ regulates the transcriptional activation on GLUT-1, GLUT-3, hexokinase gene [61]-[63] and also regulates Lactate dehydrogenase (LDHA) and monocarboxylate transporter 4 (MCT4) [61] [64] and enables the rate of anaerobic glycolysis to be increased several fold in cancer. It enables glycolytic intermediates to be used for synthesis of nucleotides and lipids [65]. HIF-1 $\alpha$ also activates pyruvate dehydrogenase kinase 1 (PDK1) thereby shunting away the pyruvate from TCA cycle, an important adaptive response to hypoxia [66] [67]. The role of MYC in modulating these metabolic effects of HIF-1 $\alpha$ have been increasingly recognized [68] [69].

\subsection{HIF and Epigenetics}

A recent study on DNA methylation in RCC revealed that RCC samples were characterized by widespread hypermethylation that preferentially affected gene bodies and enhancer regions. MOTIF analysis of aberrantly hypermethylated regions revealed enrichment for binding sites of HIF1 $\alpha$-HIF1 $\beta$ transcription factors, suggesting possible contributions of dysregulated hypoxia signaling pathways towards epigenetic changes in RCC [70].

Histone deacetylase inhibitors have been shown to repress the transactivation potential of both HIF $1 \alpha$ and HIF $2 \alpha[71]$ (Figure 1).

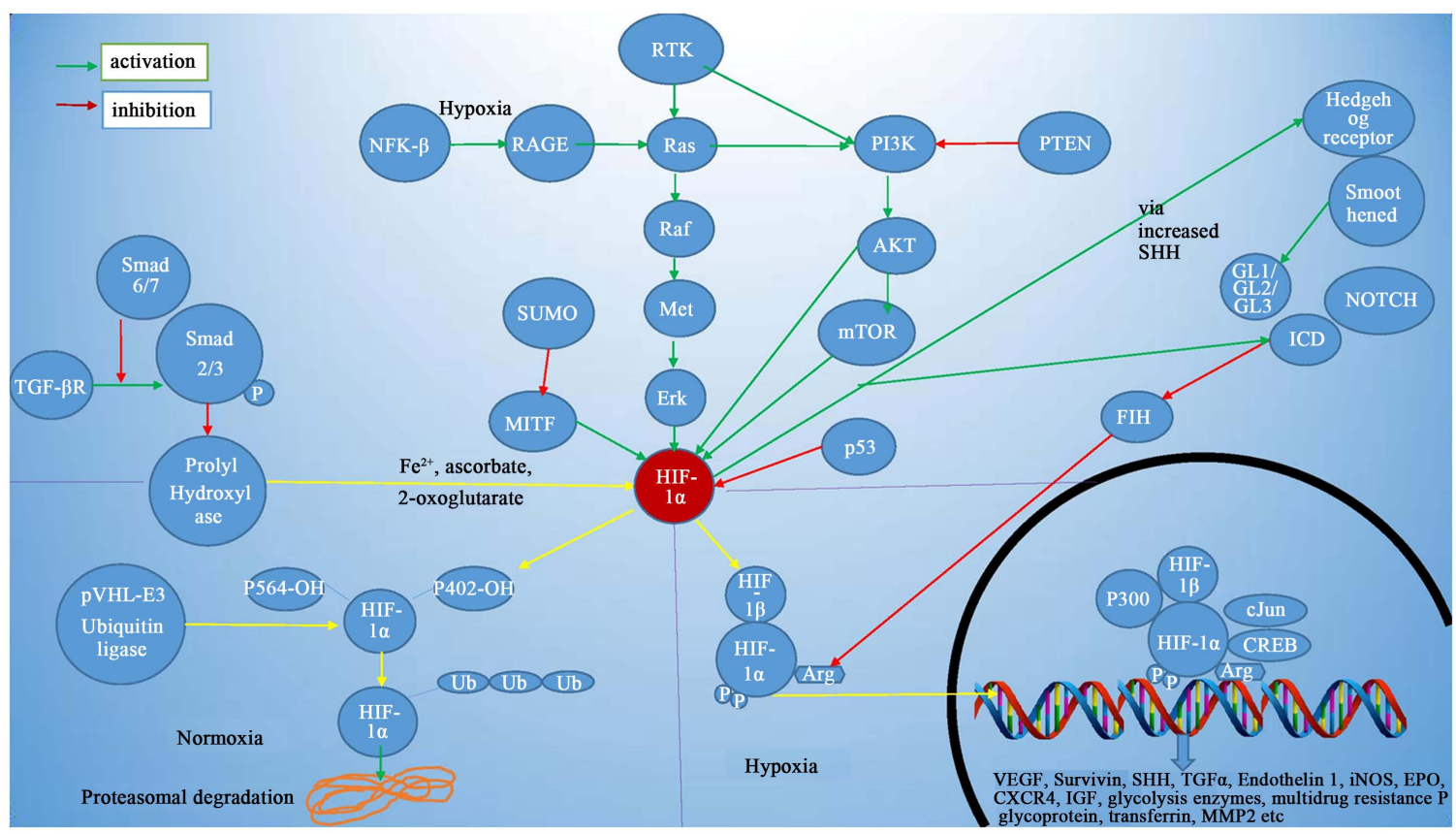

Figure 1. The regulation and interaction of HIF pathway with PI3k-AKT-mTOR, Ras-Raf-Mek-Erk, NFkB, TGF- $\beta$, Hedhehog, Notch, Microphthalmia associated transcription factor pathways, p53 and VHL; the fate of HIF $\alpha$ in normoxia and hypoxia. 


\section{Potential Cancer Therapy Strategies Targeting HIF Pathway, Downstream Signaling and Upstream Regulation}

\subsection{Simultaneous Inhibition of HIF $1 \alpha$ and HIF $2 \alpha$}

A majority of HIF pathway targeting strategies thus far have focused on the inhibition of HIF $1 \alpha$-be it indirectly via modulation of upstream regulators [72] or via small molecule inhibitors [73]-[75]. However, there is increasing evidence that HIF $2 \alpha$ plays a prominent role in some tumors and in cancer stem cells. Cancer stem cells are very resistant to radiotherapy and chemotherapy and are thought to be responsible for relapse. HIF $2 \alpha$ inhibition has also been shown to promote p53 activity, increase apoptosis and enhance radiation response [76]. Targeting HIF $2 \alpha$ with small molecule inhibitors [77] is therefore a tempting strategy. Given that HIF $1 \alpha$ and HIF $2 \alpha$ have different sets of transcriptional targets and different regulators, [72] simultaneous inhibition of both with small molecule inhibitors could reveal the complete potential of HIF pathway inhibition in cancer therapy.

\subsection{LDH-A Inhibition}

Lactate dehydrogenase isoenzyme A is one of the enzymes directly upregulated by the HIF pathway. It converts pyruvate to lactate, utilizing NADH. The upregulation of LDHA enables tumors to increase the rate of anaerobic glycolysis several fold and is by far the main source of ATP in tumors, especially in the hypoxic areas. The lactate produced is shunted out of tumor cells and used as a source of energy via gluconeogenesis in the surrounding stroma/microenvironment. The LDH isoenzyme present in RBCs, heart and brain is LDHB and a selective LDHA inhibitor would not affect these organs. The LDHA isoenzyme is found in skeletal muscle and liver. In fact, hereditary LDHA deficiency is reasonably well tolerated with the only manifestation being a mild myopathy and myoglobinuria during strenuous activity. Inhibiting LDHA has been shown to result in induction of apoptosis in cancer cells and reduced proliferation in-vitro. It has also been shown to increase the redox-sensitive anti-cancer drug EO9 induced DNA damage, with no additive effect on the normal cells [78]. LDHA is therefore considered a potentially safe and promising target in cancer therapy and clinical trials are underway to determine the safety and efficacy of its inhibition in cancer [79].

Monocarboxylate transporters (MCTs) involved in the transport of lactate and protons into and out of cells are also being considered as potential targets. MCT1 and MCT4 are overexpressed in cancers. Although MCT inhibition has shown good antitumor activity in-vitro, it could potentially cause a lot more side effects compared to LDHA inhibition, given its ubiquitous expression and its role in utilizing lactate as a substrate for gluconeogenesis and maintenance of intracellular $\mathrm{pH}$.

\subsection{Vitamin C}

Low cellular ascorbic acid has been shown to be associated with increased HIF activity and aggressive phenotype of endometrial cancer and ascorbate supplementation has been shown to suppress HIF activation by prolyl hydroxylation [80] [81]. High dose vitamin C has been studied as a treatment for cancer patients since 1970s. Laboratory and animal studies have shown that high dose vitamin $\mathrm{C}$ reduces the proliferation of colon, liver, pancreas, prostrate, malignant mesothelioma cancer cells and blocks tumor growth. It has also been shown that combining vitamin $\mathrm{C}$ with chemotherapy may be more effective than chemotherapy alone in pancreatic cancer and ovarian cancer. Clinical studies with high dose vitamin C has shown that it results in a better quality of life and fewer side effects in cancer patients on adjuvant chemotherapy and radiation. Another study showed that patients with advanced pancreatic cancer who received a combination of chemotherapy and vitamin $\mathrm{C}$ had stable disease for a few months. That effect was not replicated in studies on some other cancers and more clinical trials with vitamin C with chemotherapy are underway with a recent resurgence of interest in its potential as a therapeutic agent (http://www.cancer.gov/cancertopics/pdq/cam/highdosevitaminc/patient/page2). Recently, it was shown that HIF increases the sensitivity of the cancer cells to vitamin C induced toxicity. HIF increases the intracellular uptake of oxidized vitamin $C$ through its transcriptional target Glut 1 and reduced Vitamin $C$ though sodium dependent Vc transporters (SVCTs). The resulting high levels of vitamin C induces oxidative stress, DNA damage and depletes ATP reserves leading to cell death [82]. Interestingly, the HIF pathway has been shown to have a dominant role in pancreatic cancer, which has shown promising response to high dose vitamin C therapy in clinical trials [83]. Put together, these studies suggest that high dose vitamin C therapy may be most effective in cancers with a dominant HIF pathway. In fact, there are case reports of benefit of vitamin $\mathrm{C}$ 
therapy in renal cancer and bladder cancer, which are known to have dominant HIF pathway [84]. Determining the HIF pathway signal transduction activity in tumors and utilizing high dose vitamin $\mathrm{C}$ in addition to chemotherapy in a randomized controlled trial in a cohort of cancer patients with high HIF tumor activity, would be a very interesting study. Considering the fact that high dose vitamin $\mathrm{C}$ is well tolerated and has negligible side effects in patients with preserved renal function, it is not surprising that surveys of practitioners in United States in recent years have shown that high dose Vitamin $\mathrm{C}$ is frequently given to cancer patients.

\subsection{Targeting Upstream Regulators of the HIF Pathway}

Some chemotherapy agents inhibit upstream regulators of the HIF pathway and a part of their anticancer activity can be attributed to reduction in transcription of the HIF target genes.

Camptothecins like Topotecan and Irinotecan are DNA Topoisomerase 1 (TOP-1) inhibtors. TOP-1 inhibition leads to HIF-1 $\alpha$ down-regulation due to reduced translation [85]. Mitomycin C, another DNA damage inducing agent, is also known to reduce HIF $1 \alpha$ translation and reduce HIF $1 \alpha$ protein levels [86]. Bortezomib is a proteasome inhibitor that inhibits the degradation of many intracellular proteins including ubiquinated HIF $1 \alpha$. However, the accumulated HIF-1 $\alpha$ is inactive because of simultaneous upregulation of FIH, which inhibits the interaction of p300 with HIF $1 \alpha$ [87]. Histone deacetylase inhibitors repress the transactivation potential of both HIF $1 \alpha$ and HIF $2 \alpha$ [71]. PI3K/AKT/mTOR pathway inhibitors block the mTOR dependent kinase cascade required for HIF $1 \alpha$ mRNA translation, thereby reducing HIF $1 \alpha$ levels [88] [89].

\subsection{Inhibiting the HIF1 $\alpha$-p300 Interaction}

Inhibiting the interaction between HIF1 $\alpha$ and its transcriptional coactivators would be another approach to inhibit the downstream effects of a dysregulated HIF pathway [90]-[92].

\section{Conclusion}

The HIF pathway mediates essential features of cancer growth and survival, is constitutionally active in many cancers, and is the central driver pathway in some cancers like clear cell renal cell carcinoma. It interacts with various oncogenic pathways and understanding this complex interaction has helped in developing novel potential therapeutic strategies. A highly active HIF pathway is known to make cancers resistant to chemotherapy and radiotherapy and inhibiting the pathway could therefore potentiate the effect of these treatment modalities. Clinical trials with small molecule inhibitors of HIF $\alpha$, vitamin C, LDHA inhibitors and regulators of HIF pathway are underway.

\section{References}

[1] Semenza, G.L. (2013) HIF-1 Mediates Metabolic Responses to Intratumoral Hypoxia and Oncogenic Mutations. The Journal of Clinical Investigation, 123, 3664-3671. http://dx.doi.org/10.1172/JCI67230

[2] Jiang, B.H. and Liu, L.Z. (2008) AKT Signaling in Regulating Angiogenesis. Current Cancer Drug Targets, 8, 19-26. http://dx.doi.org/10.2174/156800908783497122

[3] Joshi, S., Singh, A.R., Zulcic, M. and Durden, D.L. (2014) A Macrophage-Dominant PI3K Isoform Controls Hypoxia-Induced HIF1alpha and HIF2alpha Stability and Tumor Growth, Angiogenesis, and Metastasis. Molecular Cancer Research, 12, 1520-1531. http://dx.doi.org/10.1158/1541-7786.MCR-13-0682

[4] Fang, J., Ding, M., Yang, L., Liu, L.Z. and Jiang, B.H. (2007) PI3K/PTEN/AKT Signaling Regulates Prostate Tumor ANGIOGENESIS. Cell Signal, 19, 2487-2497. http://dx.doi.org/10.1016/j.cellsig.2007.07.025

[5] Zhong, H., Chiles, K., Feldser, D., Laughner, E., Hanrahan, C., Georgescu, M.M., et al. (2000) Modulation of Hypoxia-Inducible Factor 1alpha Expression by the Epidermal Growth Factor/Phosphatidylinositol 3-kinase/PTEN/AKT/ FRAP Pathway in human Prostate Cancer Cells: Implications for Tumor Angiogenesis and Therapeutics. Cancer Research, 60, 1541-1545.

[6] Laughner, E., Taghavi, P., Chiles, K., Mahon, P.C. and Semenza, G.L. (2001) HER2 (neu) Signaling Increases the Rate of Hypoxia-Inducible Factor 1alpha (HIF-1alpha) Synthesis: Novel Mechanism for HIF-1-Mediated Vascular Endothelial Growth Factor Expression. Molecular and Cellular Biology, 21, 3995-4004. http://dx.doi.org/10.1128/MCB.21.12.3995-4004.2001

[7] Pore, N., Jiang, Z., Shu, H.K., Bernhard, E., Kao, G.D. and Maity, A. (2006) Akt1 Activation Can Augment Hypox- 
ia-Inducible Factor-1alpha Expression by Increasing Protein Translation through a Mammalian Target of Rapamycin-Independent Pathway. Molecular Cancer Research, 4, 471-479.

http://dx.doi.org/10.1158/1541-7786.MCR-05-0234

[8] Li, W., Qiu, T., Zhi, W., Shi, S., Zou, S., Ling, Y., et al. (2015) Colorectal Carcinomas with KRAS Codon 12 Mutation Are Associated with More Advanced Tumor Stages. BMC Cancer, 15, 340. http://dx.doi.org/10.1186/s12885-015-1345-3

[9] Kikuchi, H., Pino, M.S., Zeng, M., Shirasawa, S. and Chung, D.C. (2009) Oncogenic KRAS and BRAF Differentially Regulate Hypoxia-Inducible Factor- $1 \alpha$ and $-2 \alpha$ in Colon Cancer. Cancer Research, 69, 8499-8506. http://dx.doi.org/10.1158/0008-5472.CAN-09-2213

[10] Kang, R., Hou, W., Zhang, Q., Chen, R., Lee, Y.J., Bartlett, D.L., et al. (2014) RAGE Is Essential for Oncogenic KRAS-Mediated Hypoxic Signaling in Pancreatic Cancer. Cell Death \& Disease, 5, e1480. http://dx.doi.org/10.1038/cddis.2014.445

[11] Sun, H.L., Liu, Y.N., Huang, Y.T., Pan, S.L., Huang, D.Y., Guh, J.H., et al. (2007) YC-1 Inhibits HIF-1 Expression in Prostate Cancer Cells: Contribution of Akt/NF-KappaB Signaling to HIF-1Alpha Accumulation during Hypoxia. Oncogene, 26, 3941-3951. http://dx.doi.org/10.1038/sj.onc.1210169

[12] Kondo, K. and Kaelin Jr., W.G. (2001) The von Hippel-Lindau Tumor Suppressor Gene. Experimental Cell Research, 264, 117-125. http://dx.doi.org/10.1006/excr.2000.5139

[13] Haase, V.H. (2006) The VHL/HIF Oxygen-Sensing Pathway and Its Relevance to Kidney Disease. Kidney International, 69, 1302-1307. http://dx.doi.org/10.1038/sj.ki.5000221

[14] Pugh, C.W. and Ratcliffe, P.J. (2003) The von Hippel-Lindau Tumor Suppressor, Hypoxia-Inducible Factor-1 (HIF-1) Degradation, and Cancer Pathogenesis. Seminars in Cancer Biology, 13, 83-89. http://dx.doi.org/10.1016/S1044-579X(02)00103-7

[15] Esteban, M.A., Tran, M.G., Harten, S.K., Hill, P., Castellanos, M.C., Chandra, A., et al. (2006) Regulation of E-Cadherin Expression by VHL and Hypoxia-Inducible Factor. Cancer Research, 66, 3567-3575. http://dx.doi.org/10.1158/0008-5472.CAN-05-2670

[16] Russell, R.C. and Ohh, M. (2007) The Role of VHL in the Regulation of E-Cadherin: A New Connection in an Old Pathway. Cell Cycle, 6, 56-59. http://dx.doi.org/10.4161/cc.6.1.3668

[17] Krishnamachary, B., Zagzag, D., Nagasawa, H., Rainey, K., Okuyama, H., Baek, J.H., et al. (2006) Hypoxia-Inducible Factor-1-Dependent Repression of E-Cadherin in von Hippel-Lindau Tumor Suppressor-Null Renal Cell Carcinoma Mediated by TCF3, ZFHX1A, and ZFHX1B. Cancer Research, 66, 2725-2731. http://dx.doi.org/10.1158/0008-5472.CAN-05-3719

[18] Evans, A.J., Russell, R.C., Roche, O., Burry, T.N., Fish, J.E., Chow, V.W., et al. (2007) VHL Promotes E2 Box-Dependent E-Cadherin Transcription by HIF-Mediated Regulation of SIP1 and Snail. Molecular and Cellular Biology, 27, 157-169. http://dx.doi.org/10.1128/MCB.00892-06

[19] Sermeus, A. and Michiels, C. (2011) Reciprocal Influence of the p53 and the Hypoxic Pathways. Cell Death Disease, 2, e164. http://dx.doi.org/10.1038/cddis.2011.48

[20] Chen, D., Li, M., Luo, J. and Gu, W. (2003) Direct Interactions between HIF-1Alpha and Mdm2 Modulate p53 Function. The Journal of Biological Chemistry, 278, 13595-81359. http://dx.doi.org/10.1074/jbc.C200694200

[21] Hammond, E.M., Mandell, D.J., Salim, A., Krieg, A.J., Johnson, T.M., Shirazi, H.A., et al. (2006) Genome-Wide Analysis of p53 under Hypoxic Conditions. Molecular and Cellular Biology, 26, 3492-3504. http://dx.doi.org/10.1128/MCB.26.9.3492-3504.2006

[22] Ravi, R., Mookerjee, B., Bhujwalla, Z.M., Sutter, C.H., Artemov, D., Zeng, Q., et al. (2000) Regulation of Tumor Angiogenesis by p53-Induced Degradation of Hypoxia-Inducible Factor 1Alpha. Genes Development, 14, 34-44.

[23] Sumiyoshi, Y., Kakeji, Y., Egashira, A., Mizokami, K., Orita, H. and Maehara, Y. (2006) Overexpression of Hypoxia-Inducible Factor 1Alpha and p53 Is a Marker for an Unfavorable Prognosis in Gastric Cancer. Clinical Cancer Research, 12, 5112-5117. http://dx.doi.org/10.1158/1078-0432.CCR-05-2382

[24] Kamat, C.D., Green, D.E., Warnke, L., Thorpe, J.E., Ceriello, A. and Ihnat, M.A. (2007) Mutant p53 Facilitates Pro-Angiogenic, Hyperproliferative Phenotype in Response to Chronic Relative Hypoxia. Cancer Letters, 249, 209219. http://dx.doi.org/10.1016/j.canlet.2006.08.017

[25] Xu, Y., Li, Y., Pang, Y., Ling, M., Shen, L., Yang, X., et al. (2012) EMT and Stem Cell-Like Properties Associated with HIF-2Alpha Are Involved in Arsenite-Induced Transformation of Human Bronchial Epithelial Cells. PLoS ONE, 7, e37765. http://dx.doi.org/10.1371/journal.pone.0037765

[26] Higgins, D.F., Kimura, K., Bernhardt, W.M., Shrimanker, N., Akai, Y., Hohenstein, B., et al. (2007) Hypoxia Promotes Fibrogenesis in Vivo via HIF-1 Stimulation of Epithelial-to-Mesenchymal Transition. The Journal of Clinical Investigation, 117, 3810-3820. http://dx.doi.org/10.1172/jci30487 
[27] Mimeault, M. and Batra, S.K. (2013) Hypoxia-Inducing Factors as Master Regulators of Stemness Properties and Altered Metabolism of Cancer- and Metastasis-Initiating Cells. Journal of Cellular and Molecular Medicine, 17, 30-54. http://dx.doi.org/10.1111/jcmm.12004

[28] Du, R., Xia, L., Ning, X., Liu, L., Sun, W., Huang, C., et al. (2014) Hypoxia-Induced Bmi1 Promotes Renal Tubular Epithelial Cell-Mesenchymal Transition and Renal Fibrosis via PI3K/Akt Signal. Molecular Biology of the Cell, 25, 2650-2659. http://dx.doi.org/10.1091/mbc.E14-01-0044

[29] Guo, B.H., Feng, Y., Zhang, R., Xu, L.H., Li, M.Z., Kung, H.F., et al. (2011) Bmi-1 Promotes Invasion and Metastasis, and Its Elevated Expression Is Correlated with an Advanced Stage of Breast Cancer. Molecular Cancer, 10, 10. http://dx.doi.org/10.1186/1476-4598-10-10

[30] Yang, M.H., Hsu, D.S., Wang, H.W., Wang, H.J., Lan, H.Y., Yang, W.H., et al. (2010) Bmi1 Is Essential in Twist1Induced Epithelial-Mesenchymal Transition. Nature Cell Biology, 12, 982-992. http://dx.doi.org/10.1038/ncb2099

[31] Song, L.B., Li, J., Liao, W.T., Feng, Y., Yu, C.P., Hu, L.J., et al. (2009) The Polycomb Group Protein Bmi-1 Represses the Tumor Suppressor PTEN and Induces Epithelial-Mesenchymal Transition in Human Nasopharyngeal Epithelial Cells. The Journal of Clinical Investigation, 119, 3626-3636. http://dx.doi.org/10.1172/JCI39374

[32] Sun, S., Ning, X., Zhang, Y., Lu, Y., Nie, Y., Han, S., et al. (2009) Hypoxia-Inducible Factor-1alpha Induces Twist Expression in Tubular Epithelial Cells Subjected to Hypoxia, Leading to Epithelial-to-Mesenchymal Transition. Kidney International, 75, 1278-1287. http://dx.doi.org/10.1038/ki.2009.62

[33] Chang, L.H., Chen, C.H., Huang, D.Y., Pai, H.C., Pan, S.L. and Teng, C.M. (2011) Thrombin Induces Expression of Twist and Cell Motility via the Hypoxia-Inducible Factor-1Alpha Translational Pathway in Colorectal Cancer Cells. Journal of Cellular Physiology, 226, 1060-1068. http://dx.doi.org/10.1002/jcp.22428

[34] Wu, C.Y., Hung, J.J. and Wu, K.J. (2012) Linkage between Twist1 and Bmi1: Molecular Mechanism of Cancer Metastasis/Stemness and Clinical Implications. Clinical and Experimental Pharmacology and Physiology, 39, 668-673. http://dx.doi.org/10.1111/j.1440-1681.2011.05594.x

[35] Wu, K.J. and Yang, M.H. (2011) Epithelial-Mesenchymal Transition and Cancer Stemness: The Twist1-Bmi1 Connection. Bioscience Reports, 31, 449-455. http://dx.doi.org/10.1042/BSR20100114

[36] Wu, K.J. (2011) Direct Activation of Bmi1 by Twist1: Implications in Cancer Stemness, Epithelial-Mesenchymal Transition, and Clinical Significance. Chang Gung Medical Journal, 34, 229-238.

[37] Liu, S., Dontu, G., Mantle, I.D., Patel, S., Ahn, N.S., Jackson, K.W., et al. (2006) Hedgehog Signaling and Bmi-1 Regulate Self-Renewal of Normal and Malignant Human Mammary Stem Cells. Cancer Research, 66, 6063-6071. http://dx.doi.org/10.1158/0008-5472.CAN-06-0054

[38] Copple, B.L. (2010) Hypoxia Stimulates Hepatocyte Epithelial to Mesenchymal Transition by Hypoxia-Inducible Factor and Transforming Growth Factor-Beta-Dependent Mechanisms. Liver International, 30, 669-682. http://dx.doi.org/10.1111/j.1478-3231.2010.02205.x

[39] Han, W.Q., Zhu, Q., Hu, J., Li, P.L., Zhang, F. and Li, N. (2013) Hypoxia-Inducible Factor Prolyl-Hydroxylase-2 Mediates Transforming Growth Factor Beta1-Induced Epithelial-Mesenchymal Transition in Renal Tubular Cells. Biochimica et Biophysica Acta, 1833, 1454-1462. http://dx.doi.org/10.1016/j.bbamcr.2013.02.029

[40] Basu, R.K., Hubchak, S., Hayashida, T., Runyan, C.E., Schumacker, P.T. and Schnaper, H.W. (2011) Interdependence of HIF-1Alpha and TGF-Beta/Smad3 Signaling in Normoxic and Hypoxic Renal Epithelial Cell Collagen Expression. Renal Physiology —American Journal of Physiology, 300, F898-F905. http://dx.doi.org/10.1152/ajprenal.00335.2010

[41] Bai, H., Ge, S., Lu, J., Qian, G. and Xu, R. (2013) Hypoxia Inducible Factor-1Alpha-Mediated Activation of Survivin in Cervical Cancer Cells. Journal of Obstetrics and Gynaecology Research, 39, 555-563. http://dx.doi.org/10.1111/j.1447-0756.2012.01995.x

[42] Peng, X.H., Karna, P., Cao, Z., Jiang, B.H., Zhou, M. and Yang, L. (2006) Cross-Talk between Epidermal Growth Factor Receptor and Hypoxia-Inducible Factor-1Alpha Signal Pathways Increases Resistance to Apoptosis by Up-Regulating Survivin Gene Expression. The Journal of Biological Chemistry, 281, 25903-25914. http://dx.doi.org/10.1074/jbc.M603414200

[43] Wang, Y.F., Ma, S.R., Wang, W.M., Huang, C.F., Zhao, Z.L., Liu, B., et al. (2014) Inhibition of Survivin Reduces HIF-1Alpha, TGF-Beta1 and TFE3 in Salivary Adenoid Cystic Carcinoma. PLoS ONE, 9, e114051. http://dx.doi.org/10.1371/journal.pone.0114051

[44] Chen, S., Zhang, M., Xing, L., Wang, Y., Xiao, Y. and Wu, Y. (2015) HIF-1Alpha Contributes to Proliferation and Invasiveness of Neuroblastoma Cells via SHH Signaling. PLOS ONE, 10, e0121115. http://dx.doi.org/10.1371/journal.pone.0121115

[45] Onishi, H., Morisaki, T., Nakao, F., Odate, S., Morisaki, T. and Katano, M. (2013) Protein-Bound Polysaccharide Decreases Invasiveness and Proliferation in Pancreatic Cancer by Inhibition of Hedgehog Signaling and HIF-1Alpha 
Pathways under Hypoxia. Cancer Letters, 335, 289-298. http://dx.doi.org/10.1016/j.canlet.2013.02.041

[46] Lei, J., Ma, J., Ma, Q., Li, X., Liu, H., Xu, Q., et al. (2013) Hedgehog Signaling Regulates Hypoxia Induced Epithelial to Mesenchymal Transition and Invasion in Pancreatic Cancer Cells via a Ligand-Independent Manner. Molecular Cancer, 12, 66. http://dx.doi.org/10.1186/1476-4598-12-66

[47] Cejudo-Martin, P. and Johnson, R.S. (2005) A New Notch in the HIF Belt: How Hypoxia Impacts Differentiation. Developmental Cell, 9, 575-576. http://dx.doi.org/10.1016/j.devcel.2005.10.001

[48] Irshad, K., Mohapatra, S.K., Srivastava, C., Garg, H., Mishra, S., Dikshit, B., et al. (2015) A Combined Gene Signature of Hypoxia and Notch Pathway in Human Glioblastoma and Its Prognostic Relevance. PLoS ONE, 10, e0118201. http://dx.doi.org/10.1371/journal.pone.0118201

[49] Gustafsson, M.V., Zheng, X., Pereira, T., Gradin, K., Jin, S., Lundkvist, J., et al. (2005) Hypoxia Requires Notch Signaling to Maintain the Undifferentiated Cell State. Developmental Cell, 9, 617-628. http://dx.doi.org/10.1016/j.devcel.2005.09.010

[50] Diez, H., Fischer, A., Winkler, A., Hu, C.J., Hatzopoulos, A.K., Breier, G., et al. (2007) Hypoxia-Mediated Activation of Dll4-Notch-Hey2 Signaling in Endothelial Progenitor Cells and Adoption of Arterial Cell Fate. Experimental Cell Research, 313, 1-9. http://dx.doi.org/10.1016/j.yexcr.2006.09.009

[51] Zheng, X., Linke, S., Dias, J.M., Zheng, X., Gradin, K., Wallis, T.P., et al. (2008) Interaction with Factor Inhibiting HIF-1 Defines an Additional Mode of Cross-Coupling between the Notch and Hypoxia Signaling Pathways. Proceedings of the National Academy of Sciences of the United States of America, 105, 3368-3373. http://dx.doi.org/10.1073/pnas.0711591105

[52] Ohh, M. (2012) Tumor Strengths and Frailties: Cancer SUMmOns Otto’s Metabolism. Nature Medicine, 18, 30-31. http://dx.doi.org/10.1038/nm.2631

[53] Busca, R., Berra, E., Gaggioli, C., Khaled, M., Bille, K., Marchetti, B., et al. (2005) Hypoxia-Inducible Factor 1Alpha Is a New Target of Microphthalmia-Associated Transcription Factor (MITF) in Melanoma Cells. The Journal of Cell Biology, 170, 49-59. http://dx.doi.org/10.1083/jcb.200501067

[54] Panneerselvam, J., Jin, J., Shanker, M., Lauderdale, J., Bates, J., Wang, Q., et al. (2015) IL-24 Inhibits Lung Cancer Cell Migration and Invasion by Disrupting The SDF-1/CXCR4 Signaling Axis. PLoS ONE, 10, e0122439. http://dx.doi.org/10.1371/journal.pone.0122439

[55] Mori, T., Doi, R., Koizumi, M., Toyoda, E., Ito, D., Kami, K., et al. (2004) CXCR4 Antagonist Inhibits Stromal Cell-Derived Factor 1-Induced Migration and Invasion of Human Pancreatic Cancer. Molecular Cancer Therapeutics, 3, 29-37. http://dx.doi.org/10.1186/1476-4598-3-29

[56] Wu, H., Zhu, L., Zhang, H., Shi, X., Zhang, L., Wang, W., et al. (2015) Coexpression of EGFR and CXCR4 Predicts Poor Prognosis in Resected Pancreatic Ductal Adenocarcinoma. PLoS ONE, 10, e0116803. http://dx.doi.org/10.1371/journal.pone.0116803

[57] Phillips, R.J., Mestas, J., Gharaee-Kermani, M., Burdick, M.D., Sica, A., Belperio, J.A., et al. (2005) Epidermal Growth Factor and Hypoxia-Induced Expression of CXC Chemokine Receptor 4 on Non-Small Cell Lung Cancer Cells Is Regulated by the Phosphatidylinositol 3-Kinase/PTEN/AKT/Mammalian Target of Rapamycin Signaling Pathway and Activation of Hypoxia Inducible Factor-1Alpha. The Journal of Biological Chemistry, 280, 22473-22481. http://dx.doi.org/10.1074/jbc.M500963200

[58] Wilson, J.L., Burchell, J. and Grimshaw, M.J. (2006) Endothelins Induce CCR7 Expression by Breast Tumor Cells via Endothelin Receptor A and Hypoxia-Inducible Factor-1. Cancer Research, 66, 11802-11807. http://dx.doi.org/10.1158/0008-5472.CAN-06-1222

[59] Semenza, G.L. (2010) HIF-1: Upstream and Downstream of Cancer Metabolism. Current Opinion in Genetics Development, 20, 51-56. http://dx.doi.org/10.1016/j.gde.2009.10.009

[60] Courtnay, R., Ngo, D.C., Malik, N., Ververis, K., Tortorella, S.M. and Karagiannis, T.C. (2015) Cancer Metabolism and the Warburg Effect: The Role of HIF-1 and PI3K. Molecular Biology Reports, 42, 841-851. http://dx.doi.org/10.1007/s11033-015-3858-X

[61] Iyer, N.V., Kotch, L.E., Agani, F., Leung, S.W., Laughner, E., Wenger, R.H., et al. (1998) Cellular and Developmental Control of $\mathrm{O}_{2}$ Homeostasis by Hypoxia-Inducible Factor 1Alpha. Genes Development, 12, 149-162. http://dx.doi.org/10.1101/gad.12.2.149

[62] Chen, C., Pore, N., Behrooz, A., Ismail-Beigi, F. and Maity, A. (2001) Regulation of glut1 mRNA by Hypoxia-Inducible Factor-1. Interaction between H-ras and Hypoxia. The Journal of Biological Chemistry, 276, 9519-9525. http://dx.doi.org/10.1074/jbc.M010144200

[63] Sadlecki, P., Bodnar, M., Grabiec, M., Marszalek, A., Walentowicz, P., Sokup, A., et al. (2014) The Role of Hypoxia-Inducible Factor-1 $\alpha$, Glucose Transporter-1, (GLUT-1) and Carbon Anhydrase IX in Endometrial Cancer Patients. BioMed Research International, 2014, Article ID: 616850. 
[64] Ullah, M.S., Davies, A.J. and Halestrap, A.P. (2006) The Plasma Membrane Lactate Transporter MCT4, but Not MCT1, Is Up-Regulated by Hypoxia through a HIF-1Alpha-Dependent Mechanism. The Journal of Biological Chemistry, 281, 9030-9037. http://dx.doi.org/10.1074/jbc.M511397200

[65] Vander Heiden, M.G., Cantley, L.C. and Thompson, C.B. (2009) Understanding the Warburg Effect: The Metabolic Requirements of Cell Proliferation. Science, 324, 1029-1033. http://dx.doi.org/10.1126/science.1160809

[66] Kim, J.W., Gao, P., Liu, Y.C., Semenza, G.L. and Dang, C.V. (2007) Hypoxia-Inducible Factor 1 and Dysregulated c-Myc Cooperatively Induce Vascular Endothelial Growth Factor and Metabolic Switches Hexokinase 2 and Pyruvate Dehydrogenase Kinase 1. Molecular and Cellular Biology, 27, 7381-7393. http://dx.doi.org/10.1128/MCB.00440-07

[67] Kim, J.W., Tchernyshyov, I., Semenza, G.L. and Dang, C.V. (2006) HIF-1-Mediated Expression of Pyruvate Dehydrogenase Kinase: A Metabolic Switch Required for Cellular Adaptation to Hypoxia. Cell Metabolism, 3, 177-185. http://dx.doi.org/10.1016/j.cmet.2006.02.002

[68] Dang, C.V. (2007) The Interplay between MYC and HIF in the Warburg Effect. Ernst Schering Foundation Symposium Proceedings, 2007, 35-53.

[69] Yeung, S.J., Pan, J. and Lee, M.H. (2008) Roles of p53, MYC and HIF-1 in Regulating Glycolysis-The Seventh Hallmark of Cancer. Cellular and Molecular Life Sciences, 65, 3981-3999. http://dx.doi.org/10.1007/s00018-008-8224-x

[70] Hu, C.Y., Mohtat, D., Yu, Y., Ko, Y.A., Shenoy, N., Bhattacharya, S., et al. (2014) Kidney Cancer Is Characterized by Aberrant Methylation of Tissue-Specific Enhancers That Are Prognostic for Overall Survival. Clinical Cancer Research, 20, 4349-4360. http://dx.doi.org/10.1158/1078-0432.CCR-14-0494

[71] Fath, D.M., Kong, X., Liang, D., Lin, Z., Chou, A., Jiang, Y., et al. (2006) Histone Deacetylase Inhibitors Repress the Transactivation Potential of Hypoxia-Inducible Factors Independently of Direct Acetylation of HIF-Alpha. The Journal of Biological Chemistry, 281, 13612-13619. http://dx.doi.org/10.1074/jbc.M600456200

[72] Burroughs, S.K., Kaluz, S., Wang, D., Wang, K., Van Meir, E.G. and Wang, B. (2013) Hypoxia Inducible Factor Pathway Inhibitors as Anticancer Therapeutics. Future Medicinal Chemistry, 5, 553-572. http://dx.doi.org/10.4155/fmc.13.17

[73] Chau, N.M., Rogers, P., Aherne, W., Carroll, V., Collins, I., McDonald, E., et al. (2005) Identification of Novel Small Molecule Inhibitors of Hypoxia-Inducible Factor-1 That Differentially Block Hypoxia-Inducible Factor-1 Activity and Hypoxia-Inducible Factor-1Alpha Induction in Response to Hypoxic Stress and Growth Factors. Cancer Research, 65, 4918-4928. http://dx.doi.org/10.1158/0008-5472.CAN-04-4453

[74] Tan, C., de Noronha, R.G., Roecker, A.J., Pyrzynska, B., Khwaja, F., Zhang, Z., et al. (2005) Identification of a Novel Small-Molecule Inhibitor of the Hypoxia-Inducible Factor 1 Pathway. Cancer Research, 65, 605-612.

[75] Welsh, S.J., Dale, A.G., Lombardo, C.M., Valentine, H., de la Fuente, M., Schatzlein, A., et al. (2013) Inhibition of the Hypoxia-Inducible Factor Pathway by a G-Quadruplex Binding Small Molecule. Scientific Reports, 3, Article No. 2799. http://dx.doi.org/10.1038/srep02799

[76] Bertout, J.A., Majmundar, A.J., Gordan, J.D., Lam, J.C., Ditsworth, D., Keith, B., et al. (2009) HIF2Alpha Inhibition Promotes p53 Pathway Activity, Tumor Cell Death, and Radiation Responses. Proceedings of the National Academy of Sciences of the United States of America, 106, 14391-14396. http://dx.doi.org/10.1073/pnas.0907357106

[77] Scheuermann, T.H., Li, Q., Ma, H.W., Key, J., Zhang, L., Chen, R., et al. (2013) Allosteric Inhibition of Hypoxia Inducible Factor-2 with Small Molecules. Nature Chemical Biology, 9, 271-276. http://dx.doi.org/10.1038/nchembio.1185

[78] Allison, S.J., Knight, J.R., Granchi, C., Rani, R., Minutolo, F., Milner, J., et al. (2014) Identification of LDH-A as a Therapeutic Target for Cancer Cell Killing via (i) p53/NAD(H)-Dependent and (ii) p53-Independent Pathways. Oncogenesis, 3, e102. http://dx.doi.org/10.1038/oncsis.2014.16

[79] Doherty, J.R. and Cleveland, J.L. (2013) Targeting Lactate Metabolism for Cancer Therapeutics. The Journal of Clinical Investigation, 123, 3685-3692. http://dx.doi.org/10.1172/JCI69741

[80] Kuiper, C., Molenaar, I.G., Dachs, G.U., Currie, M.J., Sykes, P.H. and Vissers, M.C. (2010) Low Ascorbate Levels Are Associated with Increased Hypoxia-Inducible Factor-1 Activity and an Aggressive Tumor Phenotype in Endometrial Cancer. Cancer Research, 70, 5749-5758. http://dx.doi.org/10.1158/0008-5472.CAN-10-0263

[81] Flashman, E., Davies, S.L., Yeoh, K.K., Schofield, C.J. (2010) Investigating the Dependence of the Hypoxia-Inducible Factor Hydroxylases (Factor Inhibiting HIF and Prolyl Hydroxylase Domain 2) on Ascorbate and Other Reducing Agents. The Biochemical Journal, 427, 135-142. http://dx.doi.org/10.1042/BJ20091609

[82] Tian, W., Wang, Y., Xu, Y., Guo, X., Wang, B., Sun, L., et al. (2014) The Hypoxia-Inducible Factor Renders Cancer Cells More Sensitive to Vitamin C-Induced Toxicity. The Journal of Biological Chemistry, 289, 3339-3351. http://dx.doi.org/10.1074/jbc.M113.538157

[83] Chen, .J, Zhao, S., Nakada, K., Kuge, Y., Tamaki, N., Okada, F., et al. (2003) Dominant-Negative Hypoxia-Inducible 
Factor-1Alpha Reduces Tumorigenicity of Pancreatic Cancer Cells through the Suppression of Glucose Metabolism. The American Journal of Pathology, 162, 1283-1291. http://dx.doi.org/10.1016/S0002-9440(10)63924-7

[84] Padayatty, S.J., Riordan, H.D., Hewitt, S.M., Katz, A., Hoffer, L.J. and Levine, M. (2006) Intravenously Administered Vitamin C as Cancer Therapy: Three Cases. CMAJ: Canadian Medical Association Journal, 174, 937-942. http://dx.doi.org/10.1503/cmaj.050346

[85] Rapisarda, A., Uranchimeg, B., Sordet, O., Pommier, Y., Shoemaker, R.H. and Melillo, G. (2004) Topoisomerase I-Mediated Inhibition of Hypoxia-Inducible Factor 1: Mechanism and Therapeutic Implications. Cancer Research, 64, 1475-1482. http://dx.doi.org/10.1158/0008-5472.CAN-03-3139

[86] Lou, J.J., Chua, Y.L., Chew, E.H., Gao, J., Bushell, M. and Hagen, T. (2010) Inhibition of Hypoxia-Inducible Factor-1Alpha (HIF-1Alpha) Protein Synthesis by DNA Damage Inducing Agents. PLoS ONE, 5, e10522. http://dx.doi.org/10.1371/journal.pone.0010522

[87] Shin, D.H., Chun, Y.S., Lee, D.S., Huang, L.E. and Park, J.W. (2008) Bortezomib Inhibits Tumor Adaptation to Hypoxia by Stimulating the FIH-Mediated Repression of Hypoxia-Inducible Factor-1. Blood, 111, 3131-3136. http://dx.doi.org/10.1182/blood-2007-11-120576

[88] Thomas, G.V., Tran, C., Mellinghoff, I.K., Welsbie, D.S., Chan, E., Fueger, B., et al. (2006) Hypoxia-Inducible Factor Determines Sensitivity to Inhibitors of mTOR in Kidney Cancer. Nature Medicine, 12, 122-127. http://dx.doi.org/10.1038/nm1337

[89] Kondapaka, S.B., Singh, S.S., Dasmahapatra, G.P., Sausville, E.A. and Roy, K.K. (2003) Perifosine, a Novel Alkylphospholipid, Inhibits Protein Kinase B Activation. Molecular Cancer Therapeutics, 2, 1093-1103.

[90] Jayatunga, M.K., Thompson, S., McKee, T.C., Chan, M.C., Reece, K.M., Hardy, A.P., et al. (2015) Inhibition of the HIF1Alpha-p300 Interaction by Quinone- and Indandione-Mediated Ejection of Structural Zn(II). European Journal of Medicinal Chemistry, 94, 509-516. http://dx.doi.org/10.1016/j.ejmech.2014.06.006

[91] Wu, D., Zhang, R., Zhao, R., Chen, G., Cai, Y. and Jin, J. (2013) A Novel Function of Novobiocin: Disrupting the Interaction of HIF 1Alpha and p300/CBP through Direct Binding to the HIF1Alpha C-Terminal Activation Domain. PLoS ONE, 8, e62014. http://dx.doi.org/10.1371/journal.pone.0062014

[92] Cook, K.M., Hilton, S.T., Mecinovic, J., Motherwell, W.B., Figg, W.D. and Schofield, C.J. (2009) Epidithiodiketopiperazines Block the Interaction between Hypoxia-Inducible Factor-1Alpha (HIF-1Alpha) and p300 by a Zinc Ejection Mechanism. The Journal of Biological Chemistry, 284, 26831-26838. http://dx.doi.org/10.1074/jbc.M109.009498 